\title{
Factors associated with five-year survival in children with cerebral astrocytoma
}

\author{
Ricardo Arturo Sevilla-Castillo and Leticia Aradi Andrade-Sarmiento \\ Instituto Mexicano del Seguro Social, Specialty Hospital 25, Clinical Pediatrics Department, Monterrey, Mexico
}

\begin{abstract}
Introduction: The second cause of children's death is cancer, with leukemia and central nervous system tumors being the most common, among which astrocytomas account for 40\%. Objective: To find out the factors associated with 5-year survival in children with cerebral astrocytoma. Method: Case-control study nested in a retrospective cohort of patients diagnosed with cerebral astrocytoma who received treatment from December 2006 to January 2010. Descriptive statistics and the chi-square test were carried out; the Kaplan-Meier method was used to assess survival. Results: Twenty-one patients diagnosed with cerebral astrocytoma were included; survival was $76 \%$ at 5 years; with pilocytic astrocytoma being the most common (61\%); mean age was 7 years, and male gender was predominant; age at death ranged from 8 to 12 years $(p=0.022)$, with $80 \%$ of deceased patients having infratentorial localization $(O R=17.3 ; 95 \% \mathrm{Cl}=1-622 ; p=0.01)$. There was no treatment-attributable survival difference. Conclusions: Five-year survival was 76\%; the limiting risk factor is tumor infratentorial localization.
\end{abstract}

KEY WORDS: Pediatric cancer. Cerebral astrocytoma. Surveillance.

\section{Introduction}

The leading cause of death at pediatric age is accidents, followed by childhood cancer, which accounts for 0.5 to $5.7 \%$ of total malignancies in the general population. ${ }^{1}$ Leukemia constitutes the most common malignancy in children, and central nervous system (CNS) tumors the second. In Mexico, brain tumors are reported at a frequency of 10.9 to $12 \%$ and have an incidence of 3.3 to 3.5 cases per 100000 children in tertiary care medical centers, and are more common in children younger than 10 years of age, with a peak at between 4 and 6 years of age.1-3 Astrocytomas comprise the group of tumors originating in the glia; according to the American Cancer Society, these tumors account for $40 \%$ of CNS neoplasms ${ }^{4,5}$ and are the most common type. To assess treatment success, establishing survival is necessary; patients with astrocytomas have been documented to have a 5 -year survival of $85 \%$.
In the treatment of childhood cancer, risks and benefits are assessed for each patient; notwithstanding, $20 \%$ of children die and survivors have negative effects on their quality of life. ${ }^{6}$ Surgical resection is curative if fully achieved, with up to 25 years of survival, conversely to what occurs in patients in whom it is not achieved, ${ }^{7-9}$ which is influenced by the lesion anatomical localization. Patients with supratentorial tumors have been shown to have better survival when surgery is added chemotherapy and radiotherapy, with the latter being somehow controverted as regards the ideal timing to be started and the recommended dose; nevertheless, radiotherapy early initiation has been shown to prevent tumor progression, by means of which higher survival is achieved. ${ }^{10,11}$

Astrocytomas are divided in 4 grades depending on the histologic type: the pilocytic type is the most common and the one with the best prognosis; the most aggressive types are anaplastic and glioblastoma.

Currently, brain tumors are more promptly diagnosed thanks to the available imaging studies;
Correspondence:

Ricardo Arturo Sevilla-Castillo

E-mail: ricardo.sevilla@imss.gob.mx
Date of reception: 15-12-2016

Date of acceptance: 29-08-2017

DOI://dx.doi.org/10.24875/GMM.M18000143
Gac Med Mex. 2018;154:228-231

Contents available at PubMed www.gacetamedicademexico.com 
however, an increase in CNS tumors-associated mortality has been documented in recent years, especially within the first 6 years after diagnosis. ${ }^{12,13}$

With the advance of diagnostic tests and different treatment modalities for brain tumors, it is necessary for expectable survival time and influencing factors to be known, particularly in cerebral astrocytomas in children. The purpose of our study was to assess the factors associated with 5-year survival in this group of patients.

\section{Method}

This was a longitudinal, retrospective, observational, analytical study that included all patients diagnosed with CNS astrocytoma in a 5-year period from January 2006 to December 2010 at Specialty Hospital 25 in Monterrey, Nuevo León. Patient charts were used to obtain the following data: gender, age at diagnosis, anatomical region of tumor site, histopathologic study, administered treatment, time elapsed since diagnosis, chemotherapy and number of sessions, surgical treatment and whether radiotherapy was administered or not, as well as months elapsed until death. Analyses were carried out using the SPSS software, version 17.0. The chi-square test and Fischer's exact probability test were used; the Kaplan-Meier method was used to assess survival and, to assess the magnitude of association of the different risk factors, the odds ratio (OR) with its $95 \%$ confidence interval $(\mathrm{Cl})$ was measured, with a $p$-value $<0.05$ being regarded as significant.

\section{Results}

Twenty-one patients diagnosed with cerebral astrocytoma between January 2006 and December 2010 were included, out of which 16 were alive at 5 years of follow-up and 5 had died, which represented $75 \%$ of survival (Fig. 1). Of total patients, 11 (52\%) were males; the population had an age range of 2 to 12 years, with a mean of 7 years; the patients who survived had a mean age of 6 years, with a range of 2 to 11 years; those who died had a mean age of 9 years, ranging from 8 to 12 years $(p=0.02)$.

Of the 21 patients diagnosed with cerebral astrocytoma, $13(61 \%)$ were found to correspond to the pilocytic astrocytoma diagnosis, $4(19 \%)$ to the diffuse type, $2(9.5 \%)$ to anaplastic and $2(9.5 \%)$ to glioblastoma. As for anatomical site, 14 (66 \%) had supratentorial localization and 7 (33\%) infratentorial. Of the patients who survived, $13(81 \%)$ had supratentorial localization

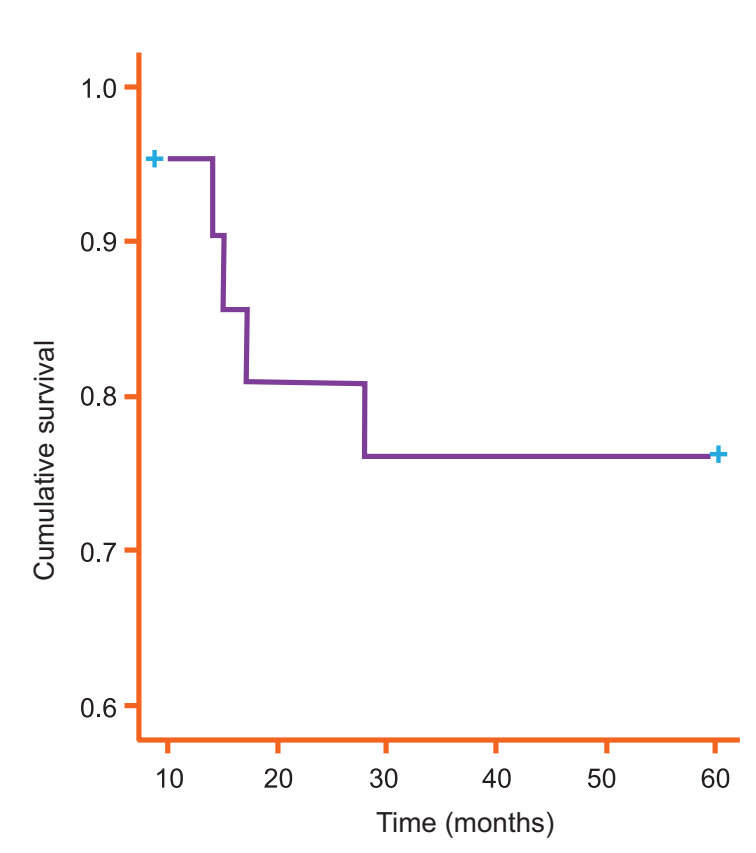

Figure 1. Five-year survival of 21 pediatric patients diagnosed with astrocytoma.

and $3(18 \%)$ infratentorial; of those who died, one (20\%) had supratentorial localization and $4(80 \%)$ infratentorial $(\mathrm{OR}=17.3 ; 95 \% \mathrm{Cl}=1-622, \mathrm{p}=0.01)$.

Seventeen patients $(80 \%)$ received treatment with chemotherapy, out of which $12(75 \%)$ survived and $5(100 \%)$ died $(p=0.22) ; 20$ patients underwent a surgical procedure, out of which $12(57 \%)$ hadpartial resection and $8(38 \%)$, complete resection (Table 1).

\section{Discussion}

In this study, among all tumors that were diagnosed in the CNS, astrocytoma was found to remain with $30 \%$ and to be the most common in the male gender.

Astrocytomas are diagnosed in $20 \%$ of patients with ages ranging from 0 to 14 years, but the most common age range is from 4 to 6 years. ${ }^{1,3,14}$ According to Bandopadhayay et al., ${ }^{15}$ one factor of poor prognosis is age at diagnosis: mortality is higher in children $<2$ years of age. We found that average age at diagnosis was 7 years and that patients who died were $<9$ years' old.

According to the World Health Organization, astrocytoma is histologically classified in 4 degrees, with the pilocytic type being the most common and the one with the best prognosis; ${ }^{16}$ our findings were consistent with those described in the world literature. Pilocytic astrocytoma was the most common histological variety in the patients who died: 13 of the 21 patients had this histological variety (61\%), and of the 5 who died, 3 had a histological diagnosis of pilocytic astrocytoma 
Table 1. Clinical characteristics and treatment of 21 astrocytoma-diagnosed pediatric patients according to 5-year survival

\begin{tabular}{|c|c|c|c|c|c|c|c|}
\hline & \multirow{2}{*}{\multicolumn{2}{|c|}{$\begin{array}{c}\text { Total } \\
(n=21)\end{array}$}} & \multirow{2}{*}{\multicolumn{2}{|c|}{$\begin{array}{c}\text { Alive } \\
(n=16)\end{array}$}} & \multirow{2}{*}{\multicolumn{2}{|c|}{$\begin{array}{l}\text { Dead } \\
(n=5)\end{array}$}} & \multirow{3}{*}{ 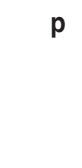 } \\
\hline & & & & & & & \\
\hline & $\mathrm{n}$ & $\%$ & $\mathrm{n}$ & $\%$ & $\mathrm{n}$ & $\%$ & \\
\hline \multicolumn{8}{|l|}{ Gender } \\
\hline Male & 11 & 5 & 8 & 50 & 3 & 60 & \multirow{2}{*}{0.702} \\
\hline Female & 10 & 48 & 8 & 50 & 2 & 40 & \\
\hline \multicolumn{7}{|l|}{ Histopathologic study } & (c) \\
\hline Pilocytic & 13 & 61 & 10 & 62.5 & 3 & 60 & \multirow[t]{4}{*}{0.429} \\
\hline Diffuse & 4 & 19 & 4 & 25 & 0 & 0 & \\
\hline Anaplastic & 2 & 9.5 & 1 & 6.2 & 1 & 20 & \\
\hline Glioblastoma & 2 & 9.5 & 1 & 6.2 & 1 & 20 & \\
\hline \multicolumn{7}{|l|}{ Anatomical region } & $\underline{\partial}$ \\
\hline Supratentorial & 14 & 66 & 13 & 81 & 1 & 20 & \multirow{2}{*}{0.013} \\
\hline Infratentorial & 7 & 33 & 3 & 18 & 4 & 80 & \\
\hline Chemotherapy & 17 & 80 & 12 & 75 & 5 & 100 & 0.225 \\
\hline Radiotherapy & 7 & 33 & 5 & 31.2 & 2 & 40 & 0.723 \\
\hline \multicolumn{8}{|l|}{ Surgical resection } \\
\hline Partial & 12 & 57 & 8 & 50 & 4 & 80 & 0.248 \\
\hline \multirow[t]{2}{*}{ Total } & 8 & 38 & 7 & 43 & 1 & 20 & 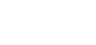 \\
\hline & Median & Min.-max. & Median & Min.-max. & Median & Min.-max. & 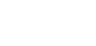 \\
\hline Age at diagnosis (years) & 7 & $2-12$ & 6 & $2-11$ & 9 & $8-12$ & 0.022 \\
\hline Time on radiotherapy (months) & 24 & $1-48$ & 6 & $1-48$ & 9 & $1-17$ & 0.769 \\
\hline Time from diagnosis to surgery (months) & 1 & $0.5-6$ & 1 & $0.5-3$ & 1 & $0.5-6$ & 0.420 \\
\hline Chemotherapy sessions & 7 & $1-14$ & 6 & $1-14$ & 7 & $1-12$ & 0.980 \\
\hline
\end{tabular}

and localization was infratentorial; as regards the two remaining patients, one showed the anaplastic variety and, the other, glioblastoma. In 2015, Samaan et al. ${ }^{13}$ observed high mortality within the first 2 years after diagnosis owing to tumor aggressiveness.

In 2008, Osorio et al. reported a survival rate of $90 \%$ in patients with complete resection of the lesion; in our population, we found no differences between different therapeutic modalities (chemotherapy, radiotherapy and surgical resection) in terms of survival; however, supratentorial tumor location was found to be a factor of good prognosis; it might be that there is surgical benefit associated with a more accessible surgical procedure in the supratentorial than in the infratentorial region. Bandopadhayay et al. ${ }^{15}$ found that the type of astrocytoma resection (partial or complete) did not influence on survival, a situation that was observed in our population.

The different treatment modalities in our study, such as chemotherapy, radiotherapy or surgical resection, showed no relevance for survival as independent variables; however, Bandopadhayay et al. ${ }^{15}$ analyzed the databases of children diagnosed with low-grade astrocytoma who survived, and observed that when resection was partial and the children received radiotherapy the results were poor; they concluded that probably this result was due to radiotherapy side effects. ${ }^{15}$

Our population showed a survival of $76 \%$, with higher probability to die in the first 2 years after diagnosis; once the 2 years had elapsed, the likelihood for staying alive was extended to more than 5 years. In a multi-center study carried out in 1994, Geyer et al. ${ }^{7}$ compared anaplastic tumors and glioblastomas during the first 2 years after diagnosis and observed a survival of $75 \%$; in their research conducted in 2013, Bandopadhayay et al..$^{15}$ observed that patients with low-grade astrocytoma achieved a survival of $85 \%$; in turn, the American Cancer Society attributes a probability of survival of $85 \%$ in children with cerebral astrocytoma. ${ }^{18}$ In view of the above, we concluded that 5-year survival in our population was slightly lower than that reported in the world literature.

\section{References}

1. Secretaría de Salud. Diagnóstico, tratamiento y prevención de los tumores cerebrales infantiles en el primer y segundo nivel de atención. 
Guía de práctica clínica. México: Secretaría de Salud/Secretaría de la Defensa Nacional/Secretaría de Marina; 2015.

2. Martínez-González MJ, García-Ribes A, Garaizar-Axpe C. Tumores cerebrales infantiles: diagnóstico y semiología neurológica. España: Asociación Española de Pediatría; 2016.

3. Trujillo, C. Basic Concepts of oncology. Medwave. 2003;9(3):e3274.

4. Chico-Ponce-De-León F, Castro-Sierra E, Perezpeña-Diazconti M, Gordillo-Domínguez LF, Santana-Montero BL, Rocha-Rivero LE, et al. Tumores intracraneanos del niño. Bol Med Hosp Infant Mex. 2006;63: 367-381.

5. Hospital Infantil de México Federico Gómez. Astrocitomas de bajo y alto grado: Guías clínicas. México: Hospital Infantil de México Federico Gómez; 2016. Disponible en: http://himfg.com.mx/descargas/documentos/ planeacion/guiasclinicasHIM/AstrocitomasBAG.pdf

6. Smith MA, Seibel NL, Altekruse SF, Ries LA, Melbert DL, O'Leary M, et al. Outcomes for children and adolescents with cancer: challenges for the twenty-first century. J Clin Oncol. 2010;28(15):2625-2634.

7. Geyer JR, Finlay JL, Boyyett JM, Wisoff J, Yates A, Mao L, et al. Survival of infants with malignant astrocytomas. A report from the Childrens Cancer Group. Cancer. 1995;75(4):1045-1050.

8. Balmaceda C, Modak S, Finlay J. Central nervous system germ cell tumors. Semin Oncol. 1998;25:243-250.

9. Berger MS, Deliganis AV, Dobbins J, Keles GE. The effect of extent of resection on recurrence in patients with low grade cerebral hemisphere gliomas. Cancer. 1994;74(6):1784-1791.

10. Karim AB, Matt B, Hatlevoll R, Menten J, Rutten EH, Thomas DG, et al. $A$ randomized trial on dose-response in radiation therapy of low-grade cerebral glioma: European Organization for Research and Treatment of Cancer (EORTC) study 22844. Int $J$ Radiat Oncol Biol Phys. 1996;36(3):549-556.

11. Pollack IF, Hurtt M, Pang D, Albright AL. Dissemination of low grade intracranial astrocytomas in children. Cancer. 1994;77(11):2869-2878.

12. Leibel SA, Sheline GE, Wara WM, Boldrey EB, Nielsen SL. The role of radiation therapy in the treatment of astrocytomas. Cancer. 1975;35: 1551-1557.

13. Samaan MC, Akhtar-Danesh N. The impact of age and race on longevity in pediatric astrocytic tumors: a population-based study. Pediatr Blood Cancer. 2015;62:1567-1571.

14. Secretaría de Salud. Tratamiento de astrocitoma y meduloblastoma en niños y adolescentes en tercer nivel de atención. Guía de práctica clínica. México: Secretaría de Salud/Secretaría de la Defensa Nacional/ Secretaría de Marina; 2015.

15. Bandopadhayay P, Bergthold G, London WB, Goumnerova LC, Morales-La Madrid A, Marcus KJ, et al. Long-term outcome of 4,040 children diagnosed with pediatric low-grade gliomas: an analysis of the Surveillance Epidemiology and End Results (SEER) database. Pediatr Blood Cancer. 2014;61(7):1173-1179.

16. Kleihues P, Burger PC, Scheithauer BW. The new WHO classification of brain tumours. Brain Pathol. 1993;3(3):255-268.

17. Osorio F, Novoa F, Dalbosco D, et al. Caso clínico: astrocitoma pilocítico. Rev Ped Elec. 2008;5(3):49-53.

18. National Cancer Institute. Surveillance, Epidemiology, and End Results (SEER) Program. Population estimates used in NCl's SEER ${ }^{*}$ Stat software. Disponible en: http://seer.cancer.gov/popdata/methods.html 